\title{
Genetic parameters for two selection criteria for feed efficiency in rabbits ${ }^{1}$
}

\author{
L. Drouilhet,*2 H. Gilbert, $\uparrow$ E. Balmisse, + J. Ruesche,* A. Tircazes, * C. Larzul, $\S$ and H. Garreau* \\ *INRA, UR 631 SAGA, Auzeville, F-31326, Castanet-Tolosan, France; †INRA, UMR 444 LGC \\ Auzeville, F-31326, Castanet-Tolosan, France; \$INRA, UE 1322 PECTOUL PEA Cunicole Toulousain, \\ Auzeville, F-31326, Castanet-Tolosan, France; and §INRA, UMR 1313 GABI, F-78352, Jouy-En-Josas, France
}

\begin{abstract}
Improvement of feed efficiency can be achieved by genetic selection directly on feed to BW gain ratio or for alternative traits. In the present study, 2 different traits were explored in the growing rabbit and their heritability and genetic correlations with traits recorded between weaning ( $30 \mathrm{~d})$ and $63 \mathrm{~d}$ of age: i) residual feed intake (RFI), to select animals having low ad libitum feed intake independently from their production level, and ii) ADG under restricted feeding $\left(\mathrm{ADG}_{\mathrm{R}}\right.$; with a restriction level of $80 \%$ compared with ad libitum feeding of a control group), to select animals having high growth rate despite limited feed intake. To study these traits, 2 rabbit lines were established named i) ConsoResidual line and ii) ADGrestrict line. Under ad libitum or restricted feeding, it comes to select animals that waste less energy for maintenance, metabolism, or activity and retain more for tissue deposition. The selection process was similar in both lines. Data comprised records from generations 0 to 6 for about 1,800 rabbits per line measured for their BW at weaning and $63 \mathrm{~d}$ of age (BW63) and their individual feed consumption. Under ad libitum feeding, the heritability estimates were moderate for RFI $(0.16 \pm 0.05)$, ADG
\end{abstract}

$(0.19 \pm 0.05)$, and feed conversion ratio (FCR; $0.22 \pm$ $0.05)$. The high genetic correlation estimated between RFI and FCR $(0.96 \pm 0.03)$ was in accordance with the literature. The genetic correlation between RFI and ADG traits was not significant. Thus, selection for low RFI with ad libitum feeding was confirmed as a potential trait to improve FCR and reduce feed intake, with little effect on ADG. To our knowledge, there is no previous selection experiment on growing rabbits with restricted feeding. Our heritability estimates for $\mathrm{ADG}_{\mathrm{R}}$ and feed conversion ratio under restricted feeding (FCRR) were moderate $(0.22 \pm 0.06$ and $0.23 \pm 0.07$, respectively $)$ and had very high negative genetic correlation. Both selection criteria were found with high and favorable genetic correlations with feed efficiency recorded under each feeding regimen. However, their different genetic correlations with BW at weaning and at $63 \mathrm{~d}$ of age $\left(\mathrm{BW} 63_{\mathrm{R}}\right.$; respectively, 0.85 and 0.17 for RFI and -0.25 and 0.81 for $\mathrm{ADG}_{\mathrm{R}}$ ) suggested different impacts on major production traits that need further analyses to decipher the relative advantages of the 2 selection criteria, together with interactions between genotypes and feeding regimen.

Key words: genetic selection, growth rate, rabbit, residual feed intake, restricted feed intake

(C) 2013 American Society of Animal Science. All rights reserved.

J. Anim. Sci. 2013.91:3121-3128 doi:10.2527/jas2012-6176

\section{INTRODUCTION}

Feed represents around $60 \%$ of production costs for rabbit breeding in France. Therefore, improving feed efficiency in rabbit farms (i.e., reducing the feed

\footnotetext{
${ }^{1}$ The authors are grateful to the staff of PECTOUL experimental unit for the breeding management. They also thank the computer engineer team of the SAGA.

${ }^{2}$ Corresponding author: laurence.drouilhet@toulouse.inra.fr

Received December 13, 2012.

Accepted April 3, 2013.
}

to $\mathrm{BW}$ gain ratio during growth) is a major issue for rabbit production. It is expected primarily to reduce feed costs but also to reduce animal excretion and to reduce the environmental impact of the production. Improvement of feed efficiency can be achieved by selection (Larzul and De Rochambeau, 2005) directly on feed to BW gain ratio or for alternative traits. The first very widely used possibility is the selection for lean growth rate on ad libitum feeding to reduce feed conversion ratio, taking advantage of favorable genetic correlation of feed conversion ratio with both leanness 
and growth rate (e.g., Nguyen et al., 2004, in pigs). A second possibility is to select animals for reduced residual feed intake (RFI) on ad libitum feeding, as proposed for the first time by Koch et al. (1963). Residual feed intake represents the fraction of total feed intake that is unexplained by maintenance requirements and growth needs. In beef, for similar growth performances, animals with a low RFI need less feed for protein turnover, tissue metabolism, stress, or activity than animals with a high RFI (Richardson and Herd, 2004). Such selection criterion has been applied to growing animals in different species: cattle (Arthur et al., 2001; Korver et al., 1991), rabbit (Larzul and De Rochambeau, 2005), pig (Cai et al., 2008; Gilbert et al., 2007), or fish (Silverstein et al., 2005). A different criterion, the residual gain, is maximizing lean growth rate corrected for feed intake under ad libitum feeding (Holder and Lamberson, 1995). Finally, a possibility is, among animals receiving the same amount of feed, to select those expressing the fastest growth rate. This requires a restricted feeding strategy to ensure that animals eat the same amount of feed and that difference for growth rate is due to feed efficiency. To our knowledge, there is no previous selection experiment on growing rabbits with restricted feeding.

To get insights into alternative selection criterion for feed efficiency, we created 2 rabbit lines: the ConsoResidual line was selected for RFI under ad libitum feeding and the ADGrestrict line was selected for ADG on restricted feeding $\left(\mathbf{A D G}_{\mathbf{R}}\right)$. This study presents the heritability estimates of these 2 feed efficiency traits, and their genetic correlations with major traits of interest recorded during the growing period under ad libitum or restricted feeding.

\section{MATERIAL AND METHODS}

\section{Animals}

The experimental rabbit populations were issued from the INRA 1001 line (Larzul and De Rochambeau, 2005) and bred at the experimental INRA farm Pôle d'Expérimentation Cunicole Toulousain (CastanetTolosan, France), in accordance with the national regulations for human care and use of animal in research.

\section{Lines Creation and Management}

Line Founders. The ConsoResidual and ADGrestrict line founders are issued from a base population structured in 9 sire families with 90 dams equally distributed in these families. Animals from 2 successive litters (batches) were chosen at weaning among 150 litters with at least 4 offspring. One male and 1 female young rabbit, having BW close to the average litter weight, were retained in each litter to be measured for each line. The first tested batch was thus of about 150 animals per line, and a second batch of same size was tested $42 \mathrm{~d}$ later. This subset of around 300 animals per line constituted the first generation, called G0. These generations were called G1 and so on until G6.

Selection from the first generation (G0) to the seventh generation (G6). The 2 lines were bred simultaneously in the same breeding unit. For each generation, 54 females in each line were inseminated with 9 males in 2 successive parities (interval of $42 \mathrm{~d}$ ), corresponding to 2 breeding batches. In each batch and for each line, about 75 male and 75 female candidates to selection born from inseminations 2 or 3 were tested, except for G5 in which the candidates for sanitary reasons were born from inseminations 4 and 5 .

After weaning at $30 \mathrm{~d}$, candidates to selection were put into individual cages ( $44 \mathrm{~cm}$ width, $30 \mathrm{~cm}$ length, and $31 \mathrm{~cm}$ height). Animals from the ConsoResidual line had ad libitum access to feed. Animals from the ADGrestrict line received restricted feed (see below). The same commercial pelleted diet (16.5\% protein and $10.6 \mathrm{MJ} / \mathrm{kg}$ $\mathrm{ME}$ ) was given to both lines. During the growing period, the diet was supplemented with antibiotics [tiamulin $(1 \%)$ and colistin (1.2\%)] to limit gut disorders.

In each line, selected sires and dams were assigned to 9 reproduction groups. Males belonged to the same reproduction group as their sire whereas females were randomly distributed among 8 groups, avoiding the group in which they were born.

The present analysis of G0 to G6 individuals includes 1,804 animals tested in the ConsoResidual line and 1,716 animals tested in the ADGrestrict line.

\section{Traits Recorded}

For the 2 lines, the BW at weaning ( $30 \mathrm{~d}$ of age) and at $63 \mathrm{~d}$ of age (BW63 for the ConsoResidual line and $\mathbf{B W 6 3} \mathbf{R}_{\mathbf{R}}$ for the ADGrestrict line) were recorded. The ADG (ADG for the ConsoResidual line and $\mathrm{ADG}_{\mathrm{R}}$ for the ADGrestrict line) for this period was computed. The individual feed consumptions were measured from $30 \mathrm{~d}$ to $63 \mathrm{~d}$ by weighing distributed feed during the whole period and weighing refusals at $63 \mathrm{~d}$ of age. Feed conversion ratio (FCR for the ConsoResidual line and $\mathbf{F C R}_{\mathbf{R}}$ for the ADGrestrict line) was calculated as total feed consumption divided by $\mathrm{BW}$ gain.

\section{Selection Criteria}

In both lines, animals were selected on their estimated breeding value computed for each selection criteria using the ASReml software (Gilmour et al., 2009). In both lines, the models were computed based on the results of the G0 generation, with heritability $\left(h^{2}\right)=0.20$ for both criteria 
and the fixed effects were batch, sex, parity, and litter size at weaning. A random effect of the common environment of the litter was also included.

In the ConsoResidual line, males and females were selected for low RFI. The RFI was computed as the residual of the multiple linear regression of total feed consumption on average metabolic weight (average BW between 30 and $63 \mathrm{~d}$ to the power 0.75 ) to account for maintenance requirements and daily $\mathrm{BW}$ gain between 30 and $63 \mathrm{~d}$ of age to account for production requirements. The coefficients of the regression equation were estimated for each generation (REG procedure; SAS Inst. Inc., Cary, NC). For example, the equation in G2 generation was $\left(R^{2}=0.66\right)$ :

$$
\begin{aligned}
\text { Feed intake }= & 244+1.15 \times \mathrm{ADG}+10.85 \times \\
& (\text { average } \mathrm{BW})^{0.75}+\mathrm{RFI},
\end{aligned}
$$

in which feed intake, average BW, and RFI were measured in grams and $\mathrm{ADG}$ was measured in grams per day.

In the ADGrestrict line, males and females were selected for high ADG from 30 to $63 \mathrm{~d}$ on restricted feeding. To keep the level of feeding restriction constant, the feed amount delivered to the animals was adjusted weekly to $80 \%$ of the amount eaten during the week before by 20 control animals raised in the same room with ad libitum access to feed. Despite the absence of variation of feed intake between the animals on restricted feeding within each generation, RFI in this line was also estimated. The multiple linear regression of total feed consumption on average metabolic weight and daily BW gain was obtained as described for the ConsoResidual line, with a different equation estimated for each generation.

\section{Statistical Analyses}

The analyses were performed independently for the 2 lines. First, the fixed effects and random effects to include in the genetic analyses were tested using a mixed linear model (MIXED procedure of SAS). For all traits, within the 2 lines, the fixed effects tested were batch (14 levels), sex (2 levels), parity (3 levels: second, third, and greater than 3$)$, the litter size at weaning (5 levels: fewer than 5,5 to 6,7 to 8,9 to 10 , and more than 10), and the interaction between batch $\times$ litter size at weaning. Only the effects with a $P$-value $<0.05$ were retained in further variance components estimations. A random effect of the common environment of the litter was also included.

In the ADGrestrict line, the batch effect was retained for all traits. For the BW at $30 \mathrm{~d}$ and $\mathrm{BW} 63_{\mathrm{R}}$, parity, litter size at weaning, and the interaction batch $\times$ litter size at weaning were added.
In the ConsoResidual line, batch, sex, and parity effects were retained for all traits. For the weight at $30 \mathrm{~d}$ or BW63, the litter size at weaning was added.

The genetic parameters were estimated by the REML methodology applied to an animal model for all traits with the fixed effects as mentioned above and 2 random effects, the common environment of the litter and the animal additive effects, using the ASReml software (Gilmour et al., 2009). At first, variance components for each trait were estimated in bivariate analyses including the selection criteria to properly account for the effect of selection (Hofer, 1998). To estimate the genetic correlations between all pairs of traits, 3-trait analyses were performed, also systematically including the selection criteria. The pedigree file included G0 to G6 animals and up to 5 generations of ancestors in each line, corresponding to a total of 2,150 animals in the ConsoResidual line and 2,110 in the ADGrestrict line.

\section{RESULTS}

\section{Descriptive Statistics}

Numbers of recorded animals per line and generation are reported in Table 1. Descriptive statistics of measured traits in the 2 lines from generations 0 to 6 are given in Tables 2 and 3. The average individual ad libitum feed consumption of the ConsoResidual line animals was $5,238 \mathrm{~g}(\mathrm{SD}=663 \mathrm{~g})$ over $33 \mathrm{~d}$. In the ADGrestrict line, the individual feed consumption is fixed for each batch; its average among the 14 batches was 3,756 g (SD = $270 \mathrm{~g}$ ). The 2 lines had on average a similar BW at $30 \mathrm{~d}$ old around $871 \mathrm{~g}(\mathrm{SD}=130 \mathrm{~g})$. The average $\mathrm{BW} 63_{\mathrm{R}}$ was lighter than the BW63 $(\mu=2,241$ and SD $=175$ vs. $\mu=2,707$ and $\mathrm{SD}=273 \mathrm{~g})$. The $\mathrm{ADG}_{\mathrm{R}}$ was $3 \mathrm{SD}$ less than $\mathrm{ADG}(\mu=40.4$ and $\mathrm{SD}=4.0$ vs. $\mu=54.1$ and $\mathrm{SD}=$ $5.5 \mathrm{~g} / \mathrm{d})$ and $\mathrm{FCR}_{\mathrm{R}}$ was moderately less than FCR $(\mu=$ 2.77 and $\mathrm{SD}=0.27$ vs. $\mu=2.86$ and $\mathrm{SD}=0.22$ ).

Table 1. Number of recorded animals by line and generation ${ }^{1}$

\begin{tabular}{lcc}
\hline \hline Generation $(\mathrm{G})$ & ADGrestrict & ConsoResidual \\
\hline G0 & 218 & 220 \\
G1 & 274 & 269 \\
G2 & 276 & 283 \\
G3 & 248 & 254 \\
G4 & 257 & 259 \\
G5 & 240 & 285 \\
G6 & 203 & 234 \\
Total & 1,716 & 1,804 \\
\hline & 1 ADGrestrict : line selected for ADG with restricted feeding. ConsoResidual \\
: line selected for RFI with ad libitum feeding.
\end{tabular}


Table 2. Descriptive statistics in the ConsoResidual line, data from generation 0 to $6^{1}$

\begin{tabular}{lcc}
\hline \hline Trait $^{2}$ & Mean & SD \\
\hline BW at weaning, g & 872 & 130 \\
BW63, g & 2,707 & 273 \\
Individual feed consumption, g & 5,238 & 663 \\
FCR & 2.86 & 0.22 \\
ADG, g/day & 54.1 & 5.5 \\
RFI, g & 0 & 313 \\
\hline${ }^{1}$ The ConsoResidual line was selected for residual feed intake (RFI) with \\
ad libitum feeding. \\
${ }^{2}$ BW63 = BW at 63 d; FCR = feed conversion ratio.
\end{tabular}

\section{Heritability Estimates of the Two Selected Lines}

Heritability estimates of the traits analyzed in the ConsoResidual and ADGrestrict are given in Tables 4 and 5, respectively. Heritabilities of the selection criteria $A D G_{R}$ in the $A D G r e s t r i c t$ line and RFI in the ConsoResidual line were moderate $(0.22 \pm 0.06$ and $0.16 \pm 0.05$, respectively).

In the ConsoResidual line, $\mathrm{ADG}$ and FCR had moderate heritability values $(0.19 \pm 0.05$ and $0.22 \pm$ 0.05 , respectively). The estimate of heritability of $F C R_{R}$ $(0.23 \pm 0.07)$ was of similar magnitude as the estimate for $\mathrm{ADG}_{\mathrm{R}}(0.22 \pm 0.06)$. Heritability estimate for RFI with restricted feeding $\left(\mathbf{R F I}_{\mathbf{R}}\right)$ was relatively low $(0.10 \pm 0.04)$ compared with the estimate for RFI in the ConsoResidual line $(0.16 \pm 0.05)$.

In the 2 lines, the heritability of the weaning BW was around 0 whereas the common environment of the litter explained a large proportion of variance of this trait $(0.32 \pm 0.04$ in the ADGrestrict line and $0.44 \pm 0.03$ in the ConsoResidual line). The heritability estimates of the $\mathrm{BW}$ at $63 \mathrm{~d}\left(\mathrm{BW} 63\right.$ and $\mathrm{BW} 63_{\mathrm{R}}$ ) were moderate (around $0.14 \pm 0.05$ for both lines). The common environment of the litter tended to explain a greater proportion of the variance of $B W 63_{R}$ in the ConsoResidual line $(0.27 \pm$ 0.03) than for BW63 in the ADGrestrict line (0.19 \pm 0.03 ). In both lines a larger proportion of the variance of the BW due to common litter environment was estimated at weaning compared with $63 \mathrm{~d}$.

Table 4. Estimates of heritability $\left(h^{2}\right)$ and common litter effects $\left(c^{2}\right)$ in the ConsoResidual line ${ }^{1}$

\begin{tabular}{lcc}
\hline \hline Trait $^{2}$ & \multicolumn{1}{c}{$h^{2}$} & $\mathrm{c}^{2}$ \\
\hline BW at weaning & $0.06(0.04)$ & $0.44(0.03)$ \\
BW63 & $0.14(0.05)$ & $0.27(0.03)$ \\
FCR & $0.22(0.05)$ & $0.13(0.03)$ \\
ADG & $0.19(0.05)$ & $0.06(0.02)$ \\
RFI & $0.16(0.05)$ & $0.05(0.02)$ \\
\hline${ }^{1}$ The ConsoResidual line was selected for residual feed intake (RFI) with \\
ad libitum feeding. \\
\multicolumn{2}{l}{${ }^{2}$ BW63 = BW at 63 d; FCR = feed conversion ratio; ( ): SE. }
\end{tabular}

Table 3. Descriptive statistics in the ADGrestrict line, data from generation 0 to $6^{1}$

\begin{tabular}{|c|c|c|}
\hline$\overline{\text { Trait }^{2}}$ & Mean & SD \\
\hline BW at weaning, $g$ & 871 & 131 \\
\hline $\mathrm{BW} 63_{\mathrm{R}}, \mathrm{g}$ & 2,241 & 175 \\
\hline $\mathrm{FCR}_{\mathrm{R}}$ & 2.77 & 0.27 \\
\hline $\mathrm{ADG}_{\mathrm{R}}, \mathrm{g} /$ day & 40.4 & 4.0 \\
\hline $\mathrm{RFI}_{\mathrm{R}}, \mathrm{g}$ & 0 & 97 \\
\hline
\end{tabular}

\section{Genetic Correlations in the Two Lines}

Tables 6 and 7 show the genetic correlations between the traits measured in the ConsoResidual line and in the ADGrestrict line, respectively. Despite relatively large SE, general tendencies can be outlined in terms of correlations.

In the ConsoResidual line, RFI was highly correlated to FCR $(0.96 \pm 0.03)$ and to the weaning weight $(0.85 \pm$ $0.34)$. Residual feed intake was not significantly correlated with ADG $(-0.09 \pm 0.20)$ and BW63 $(0.17 \pm$ $0.24)$. Average daily BW gain was highly correlated to BW63 $(0.95 \pm 0.04)$ and not significantly correlated to $\mathrm{BW}$ at weaning $(0.17 \pm 0.31)$. Average daily BW gain tended to be negatively correlated with FCR $(-0.38 \pm$ 0.18 ). Feed conversion ratio was moderately correlated to $\mathrm{BW}$ at weaning $(0.73 \pm 0.25)$ and not significantly with BW63 $(-0.11 \pm 0.23)$. The genetic correlation between the BW at weaning and BW63, in the ConsoResidual line, was moderate $(0.51 \pm 0.23)$.

In the $\mathrm{ADGrestrict}$ line, $\mathrm{ADG}_{\mathrm{R}}$ had a moderate to high genetic correlation with $\mathrm{BW}_{6} 3_{\mathrm{R}}(0.81 \pm 0.17)$ and was poorly correlated to $\mathrm{BW}$ at weaning $(-0.25 \pm 0.37)$. As animals were bred under restricted feeding, the amount of ingested food was uniform between animals in a given batch, and then by construction, $\mathrm{FCR}_{\mathrm{R}}$ was proportional to $1 / \mathrm{ADG}_{\mathrm{R}}$. Consequently, $\mathrm{FCR}_{\mathrm{R}}$ was fully negatively correlated to the $\mathrm{ADG}_{\mathrm{R}}(-1.00 \pm 0.003)$ and the genetic correlation between $\mathrm{FCR}_{\mathrm{R}}$ and the other traits were just the opposite of the correlation estimates obtained with $\mathrm{ADG}_{\mathrm{R}}$ for these traits. The genetic correlation between $\mathrm{RFI}_{R}$ and

Table 5. Estimates of heritability $\left(h^{2}\right)$ and common litter effects $\left(\mathrm{c}^{2}\right)$ in the ADGrestrict line ${ }^{1}$

\begin{tabular}{lcc}
\hline \hline Trait ${ }^{2}$ & \multicolumn{1}{c}{$h^{2}$} & $\mathrm{c}^{2}$ \\
\hline $\mathrm{BW}$ at weaning & $0.05(0.05)$ & $0.32(0.04)$ \\
$\mathrm{BW63}{ }_{\mathrm{R}}$ & $0.14(0.06)$ & $0.19(0.03)$ \\
$\mathrm{FCR}_{\mathrm{R}}$ & $0.23(0.07)$ & $0.18(0.03)$ \\
$\mathrm{ADG}_{\mathrm{R}}$ & $0.22(0.06)$ & $0.17(0.03)$ \\
$\mathrm{RFI}_{\mathrm{R}}$ & $0.10(0.04)$ & $0.17(0.03)$ \\
\hline${ }^{1}{ }_{\mathrm{The}} \mathrm{ADGrestrict}$ line was selected for ADG with restricted feeding $\left(\mathrm{ADG}_{\mathrm{R}}\right)$. \\
${ }^{2} \mathrm{BW} 63_{\mathrm{R}}=\mathrm{BW}$ at $63 \mathrm{~d}$ with restricted feeding; $\mathrm{FCR}_{\mathrm{R}}=$ feed conversion ratio \\
with restricted feeding; $\mathrm{RFI}_{\mathrm{R}}=$ residual feed intake with restricted feeding; ( ): SE.
\end{tabular}


Table 6. Estimates of genetic correlations in the ConsoResidual line ${ }^{1}$

\begin{tabular}{lcccc}
\hline \hline Trait $^{2}$ & Weaning weight & BW63 & ADG & FCR \\
\hline BW63 & $0.51(0.23)$ & & & \\
ADG & $0.17(0.31)$ & $0.95(0.04)$ & & \\
FCR & $0.73(0.25)$ & $-0.11(0.23)$ & $-0.38(0.18)$ & \\
RFI & $0.85(0.34)$ & $0.17(0.24)$ & $-0.09(0.20)$ & $0.96(0.03)$ \\
\hline
\end{tabular}

${ }^{1}$ The ConsoResidual line was selected for residual feed intake (RFI) with ad libitum feeding.

${ }^{2} \mathrm{BW} 63=\mathrm{BW}$ at $63 \mathrm{~d} ; \mathrm{FCR}=$ feed conversion ratio, ( ): $\mathrm{SE}$.

$\mathrm{ADG}_{\mathrm{R}}$ was not significant whereas it was moderate with $\mathrm{FCR}_{\mathrm{R}}$ and it tended to be negative with $\mathrm{BW}$ at weaning and $\mathrm{BW} 63_{\mathrm{R}}$. The $\mathrm{BW}$ at weaning and $\mathrm{BW} 63_{\mathrm{R}}$, in the ADGrestrict line, were poorly correlated $(0.40 \pm 0.37)$.

The main differences concerning the genetic correlations between the 2 selection strategies are the correlations between feed conversion ratio and the other traits, between residual feed intake and the other traits, and between BW at weaning and at $63 \mathrm{~d}$.

\section{DISCUSSION}

\section{Two Different Selection Criteria}

The most widely used indirect selection criterion for feed efficiency is certainly growth rate. Its major interest is that recording or monitoring feed intake in not necessary with this option. The implications of this strategy for breeding programs have been largely documented, for example in the pig literature (Cameron, 1994), and its potential drawbacks in terms of decreased robustness of the breeding populations is reviewed in a number of papers (Prunier et al., 2010). In the present study, we compared 2 alternative traits to improve feed efficiency by selection: i) for similar growth rate, to select animals having low ad libitum feed intake (i.e., RFI), and ii) for similar amount of feed eaten, to select animals having high growth rate (i.e., ADG on restricted feeding). Under ad libitum or restricted feeding, it comes to select animals that waste less energy for maintenance, metabolism, or activity and retain more for tissue deposition.

\section{Ad Libitum Feeding}

The heritability estimate of RFI was less than the value given by Larzul and De Rochambeau (2005; $0.16 \pm 0.05$ vs. $0.45 \pm 0.11$ ) with a larger SE in a 1 -generation selection experiment. In pigs, estimates of RFI heritability range from 0.10 to 0.42 (Clutter, 2011). In these studies, RFI is calculated taking into account only ADG or both ADG and backfat thickness. In the rabbit, the low adiposity of growing animals and its
Table 7. Estimates of genetic correlations in the ADGrestrict line ${ }^{1}$

\begin{tabular}{|c|c|c|c|c|}
\hline Trait $^{2}$ & Weaning weight & $\mathrm{BW} 63_{\mathrm{R}}$ & $\mathrm{ADG}_{\mathrm{R}}$ & $\mathrm{FCR}_{\mathrm{R}}$ \\
\hline $\mathrm{BW} 63_{\mathrm{R}}$ & $0.40(0.37)$ & & & \\
\hline $\mathrm{ADG}_{\mathrm{R}}$ & $-0.25(0.37)$ & $0.81(0.17)$ & & \\
\hline $\mathrm{FCR}_{\mathrm{R}}$ & $0.24(0.37)$ & $-0.80(0.18)$ & $-1.00(0.003)$ & \\
\hline $\mathrm{RFI}_{\mathrm{R}}$ & $-0.45(0.42)$ & $-0.52(0.28)$ & $-0.19(0.27)$ & $0.43(0.29)$ \\
\hline
\end{tabular}

reduced variability compared with the lack of precision of in vivo measurements do not allow proper estimation of the part of ingestion dedicated to fat deposition in the equation of feed intake prediction (Larzul and De Rochambeau, 2005). The heritability estimate of ADG in our study was in the range of the values previously reported during the fattening period in the rabbit, from $0.11 \pm 0.02$ (Piles and Blasco, 2003) to $0.41 \pm 0.13$ (Larzul and De Rochambeau, 2005) under ad libitum feeding. Among the few heritability estimates for FCR available in the literature, estimates range from $0.25 \pm$ 0.12 (line R; Piles et al., 2004) to $0.31 \pm 0.10$ (line C; Piles et al., 2004). The value found in the present study was moderate in comparison $(0.19 \pm 0.05)$.

The very high estimate of correlation between RFI and FCR $(0.96 \pm 0.03)$ under ad libitum feeding was in accordance with the value of 1.00 given by Larzul and De Rochambeau (2005). In pigs, genetic correlations between RFI and FCR are generally also high (0.52 to 0.85; Saintilan et al., 2013). The traits RFI and ADG were not significantly correlated in our study. This correlation was similar to the estimate of Larzul and De Rochambeau (2005) in rabbits $(-0.09 \pm 0.20)$. In pigs genetic correlations between RFI and the traits used to predict feed intake are usually close to null (Hoque and Suzuki, 2009). As a conclusion from these estimates, selection for low RFI with ad libitum feeding has the potential to improve FCR and ADG would be nearly unaffected, as expected.

\section{Restricted Feeding}

To our knowledge, there are no previously published selection experiments with growing rabbits with restricted feeding with which to compare our results. Nevertheless, a selection experiment on growth rate under restricted feeding has been previously performed in pigs (Nguyen and McPhee, 2005). However, in their selection experiment, animals were restricted at a fixed amount of feed (different in summer and in winter), which remained unchanged during all the experiment. In our case, the amount of feed delivered changed with the 
genetic selection, the objective being to keep a constant restriction level over generations. Yet after 4 generations of selection, Nguyen and McPhee (2005) showed an improvement of feed efficiency, with an increase of growth rate and a decrease of spontaneous intake, even if animals were de novo fed ad libitum (Nguyen et al., 2005). Their heritability estimates for $A D G_{R}$ and $F C R_{R}$ were as moderate as ours $(0.22 \pm 0.06$ and $0.23 \pm 0.07$, respectively). Moreover, the authors described the same very high negative genetic correlation between $\mathrm{ADG}_{\mathrm{R}}$ and $\mathrm{FCR}_{\mathrm{R}}(-1.00)$. As expected, selection for growth rate with restricted feeding allowed efficient improvement of FCR $R_{R}$. However, $\mathrm{FCR}_{\mathrm{R}}$ is not FCR. As reviewed by Hermesch et al. (2004) in pigs, restricted feeding will maximize genetic improvement of lean meat growth and is superior for a breeding objective with little or no emphasis on changing feed intake. The more efficient pigs under restricted feeding would have a greater potential for lean meat growth under ad libitum feeding, together with a greater feed intake capacity that results in better feed conversion ratio.

\section{Different Feeding Strategies: Different Traits Measured}

The heritability estimate for $\mathrm{ADG}_{\mathrm{R}}$ in the ADGrestrict line was slightly greater than the estimate for RFI in the ConsoResidual line.

To gain an insight into the links between traits measured under the different feeding strategies, a joint analysis of the 2 lines was performed. Unfortunately the analysis did not converge when the full models established were considered. To simplify the models, the common litter effect was retrieved and 4-traits analysis was done, taking into account the 2 criteria of selection (RFI and $\left.\mathrm{ADG}_{\mathrm{R}}\right), \mathrm{FCR}_{\mathrm{R}}$ and FCR. Even if the estimations were not properly obtained due to the simplification of the models, the genetic correlation between $\mathrm{FCR}_{\mathrm{R}}$ and FCR tended to be high $(0.94 \pm 0.19)$. It indicates that whatever the feeding strategy chosen, in both case the FCR is improved. The high performances of selected animals are not specific of the ad libitum or restricted feeding. Therefore, as $A D G_{R}$ heritability estimate is greater than the RFI estimate, one may conclude that genetic selection on $A D G_{R}$ with restricted feeding would probably be more efficient to reduce FCR than on RFI with ad libitum feeding.

The 2 lines were submitted to different feeding strategies. In the ConsoResidual line, animals were fed ad libitum; they could therefore fulfill their voluntary feed intake and growth potential. Conversely, animals from the ADGrestrict line were bred under restricted feeding; they were selected for a more efficient use of this restricted amount of feed. As a consequence, traits such as ADG and FCR do not represent the same performance in the 2 lines. However, the estimates of heritability were of similar magnitude for homologous traits independently from the feeding status. This result was also found in pigs, as reviewed by Hermesch et al. (2004), 2 feeding regimens did not result in different heritability estimates for production traits. This suggests a genetic basis of the traits under restricted feeding of similar magnitude as under ad libitum feeding, but genetic correlations between the traits were modified by the restriction feeding.

Heritability estimates of the weaning weight in our study were low, in accordance with values previously reported by Ferraz and Eler (1994), Lukefahr et al. (1996), and Larzul and De Rochambeau (2005). Focusing on the studies with a slaughter age at $63 \mathrm{~d}$ old, our heritability estimates of the BW at $63 \mathrm{~d}$ old (BW63 and BW63 ${ }_{\mathrm{R}}$ ) were slightly less than those reported by Larzul et al. (2005; $0.22 \pm 0.02)$ and Garcia and Baselga (2002; $0.30 \pm 0.01$ ) but as expected systematically greater than those estimated at weaning.

Litter effects for BW at weaning were large. Moreover, the proportion of variance explained by the litter effect decreased over time, so that the estimates were greater for BW at weaning than BW63 and BW63 ${ }_{\mathrm{R}}$. This observation was previously made in numerous studies (Ferraz and Eler, 1994; Garcia and Baselga, 2002; Larzul and De Rochambeau, 2005; Larzul et al., 2005). The estimate of litter effects for $B W 63_{R}$ was slightly lower than BW63.

The genetic correlations between the weaning and the slaughter BW are generally quite high in the literature: Lukefahr et al. (1996) +0.56 (SE not given, slaughtering at $70 \mathrm{~d}$ ) and Larzul et al. (2005) $+0.67 \pm 0.04$ (slaughtering at $70 \mathrm{~d}$ ), as was our estimation under ad libitum feeding. However, when restricted feeding was applied, our estimate was slightly lower and not significantly different from 0 due to large SE. In this line, the weaning weight was an "ad libitum" trait whereas the BW at $63 \mathrm{~d}$ was a restricted-feeding trait. This low correlation suggests that these 2 traits might have a different genetic basis, contrary to the 2 weights measured under ad libitum feeding in the ConsoResidual line.

In the ADGrestrict line, the genetic correlation between $A D G_{R}$ and the weaning weight tended to be negative $(-0.25 \pm 0.37)$ whereas the correlation between $\mathrm{ADG}_{\mathrm{R}}$ and $\mathrm{BW63} \mathrm{R}_{\mathrm{R}}$ was high $(0.81 \pm 0.17)$. On the contrary, in the ConsoResidual line, the correlation between RFI and the weaning weight was high whereas RFI was not significantly correlated with BW63. The explanation of this high genetic correlation remains to be determined. Animals with the greatest precocious growth rate (between birth and weaning) seem to be more wasteful during the growth period studied, that is, from weaning to $63 \mathrm{~d}$ old. In terms of responses to selection, this would imply increased BW at slaughter if selection was applied under restricted feeding (or if the objective 
is a fixed slaughter BW, reduced duration of feeding, that is to say to keep animals shorter time) whereas it would not be affected in the ConsoResidual line.

As most slaughterhouses have a specific evaluation grid based on BW of animals (variation allowed in a specific range of $400 \mathrm{~g}$ in France without downgrading the carcasses), the selection of ADG under restricted feeding can only be used to increase BW at slaughter to a certain extent. However, it can be used to slaughter animals at a lower age and save a few days of building occupation. As most of the farms operate with 2 buildings, switching from maternity and rabbit growth, and as does move from 1 building to the other after weaning, the changes in breeding rhythms are limited to the reproduction cycles; if the fattening period is reduced for a few days, it will increase the duration of sanitary empty. Rabbit breeders will therefore have to decipher whether their selection objectives will include increasing growth rate in the future.

In France, growing rabbits are generally under restricted feeding to prevent the occurrence of digestive disorders after weaning. It makes sense to select animals under the same feeding strategy to create a genetic gain that will be transmitted at the production level. Restricting animals individually to the same amount of feed requires breeding rabbits in individual cages or automatic feeders with individual identification of the rabbits. The first option is costly and time consuming and therefore hardly realistic to practice for breeders. However, feed restriction can also be applied to animals bred in collective cages, but that does not guarantee that all rabbits are restricted to the same amount of feed, generating growth rate differences potentially due to greater feed intake for some animals rather than feed efficiency. Moreover, in pigs, it has been shown that feeding behavior was open to change depending on the housing mode (group vs. individual cage; de Haer and de Vries, 1993). To minimize the effect of the breeding environment, breeding rabbits in collective pens equipped with electronic feeders to record individual consumptions would be the best, even if not eliminating all interactions with feeding conditions. Choosing the appropriate selection environment, selection criteria, and breeding objectives for the breeding stock in nucleus herds has the power to maximize profit through the improved performance of their descendants in commercial production (Nguyen et al., 2004). From our study on criteria to select for feed efficiency, the main choices will stand in electing the proper testing conditions and breeding objectives for the future of rabbit production: selection for ADG under restricting feeding essentially affects growth rate and has reduced impact on reducing feed intake whereas selecting for RFI under ad libitum feeding minimizes feed intake for a given growth rate. Evaluating potential genotypes $\times$ feeding regime interactions would give complementary necessary insights into these selection choices.

\section{Conclusion}

To our knowledge, our study is the first on the genetic determinism of growth and feed efficiency traits in growing rabbits with ad libitum or restricted feeding. Heritability of $\mathrm{ADG}_{\mathrm{R}}$ with restricted feeding was slightly greater than the estimate for RFI with ad libitum feeding. The genetic correlation between those traits and the FCR were slightly different under each feeding regimen, but both were very high and favorable for selection purposes. Therefore, if breeding under restricted feeding is not an issue, a genetic selection on $\mathrm{ADG}_{\mathrm{R}}$ with restricted feeding would probably be more efficient to reduce FCR than on RFI with ad libitum feeding.

However, the genetic correlated responses with other traits were quite different in the 2 lines and were largely influenced by the feed restriction. These differences would lead to different responses to selection on traits such as BW at weaning and at $63 \mathrm{~d}$. Further studies are needed to evaluate genetic gain and responses to selection with both strategies and compare actual genetic gains when restriction is alleviated in the ADGrestrict line.

\section{LITERATURE CITED}

Arthur, P. F., J. A. Archer, D. J. Johnston, R. M. Herd, E. C. Richardson, and P. F. Parnell. 2001. Genetic and phenotypic variance and covariance components for feed intake, feed efficiency, and other postweaning traits in Angus cattle. J. Anim. Sci. 79:2805-2811.

Cai, W., D. S. Casey, and J. C. Dekkers. 2008. Selection response and genetic parameters for residual feed intake in Yorkshire swine. J. Anim. Sci. 86:287-298.

Cameron, N. D. 1994. Selection for components of efficient lean growth rate in pigs 1 . Selection pressure applied and direct responses in a Large White herd. Anim. Prod. 59:251-262.

Clutter, A. C. 2011. Genetics of performance traits. In: M. F. Rothschild and A. Ruvinsky, editors, The genetics of the pig. CAB International, Wallingford, UK. p. 325-389.

de Haer, L. C. M., and A. G. de Vries. 1993. Feed intake patterns of and feed digestibility in growing pigs housed individually or in groups. Livest. Prod. Sci. 33:277-292.

Ferraz, F. B. S., and J. P. Eler. 1994. Use of different animal models in prediction of genetic parameters of 23 traits of Californian and New Zealand White rabbits in tropics and suggestion of selection criteria. In: Proceedings of the 5th World Congress on Genetics Applied to Livestock Production, Guelph, Canada. p. 348-351.

Garcia, M. L., and M. Baselga. 2002. Estimation of correlated response on growth traits to selection in litter size of rabbits using a cryopreserved control population and genetic trends. Livest. Prod. Sci. 78:91-98.

Gilbert, H., J. P. Bidanel, J. Gruand, J. C. Caritez, Y. Billon, P. Guillouet, H. Lagant, J. Noblet, and P. Sellier. 2007. Genetic parameters for residual feed intake in growing pigs, with emphasis on genetic relationships with carcass and meat quality traits. J. Anim. Sci. 85:3182-3188. 
Gilmour, A. R., B. J. Gogel, B. R. Cullis, and R. Thompson. 2009. ASReml user guide. VSN International Ltd., Hemel Hempstead, UK.

Hermesch, S. 2004. Genetic improvement of lean meat growth and feed efficiency in pigs. Aust. J. Exp. Agric. 44:383-391.

Hofer, A. 1998. Variance component estimation in animal breeding: A review. J. Anim. Breed. Genet. 115:247-265.

Holder, R. B., and W. R. Lamberson. 1995. Selection for improved efficiency of lean gain in mice: Population and procedures. Anim. Welfare Inf. Cent. Bull. 6:14-16.

Hoque, M. A., and K. Suzuki. 2009. Genetics of residual feed intake in cattle and pigs: A review. Asian-Australas. J. Anim. Sci. 22:747-755.

Koch, R. M., L. A. Swiger, D. Chambers, and K. E. Gregory. 1963. Efficiency of feed use in beef cattle. J. Anim. Sci. 22:486-494.

Korver, S., E. A. M. van Eekelen, H. Vos, G. J. Nieuwhof, and J. A. M. van Arendonk. 1991. Genetic parameters for feed intake and feed efficiency in growing dairy heifers. Livest. Prod. Sci. 29:49-59.

Larzul, C., and H. De Rochambeau. 2005. Selection for residual feed consumption in the rabbit. Livest. Prod. Sci. 95:67-72.

Larzul, C., F. Gondret, S. Combes, and H. de Rochambeau. 2005. Divergent selection on 63-day body weight in the rabbit: Response on growth, carcass and muscle traits. Genet. Sel. Evol. 37:105-122.

Lukefahr, S. D., H. B. Odi, and J. K. A. Atakora. 1996. Mass selection for 70-day body weight in rabbits. J. Anim. Sci. 74:1481-1489.

Nguyen, N. H., and C. P. McPhee. 2005. Genetic parameters and responses of performance and body composition traits in pigs selected for high and low growth rate on a fixed ration over a set time. Genet. Sel. Evol. 37:199-213.

Nguyen, N. H., C. P. McPhee, and C. M. Wade. 2004. Genetic selection strategies for efficient lean growth in pigs. Pig News Inf. $25: 149 \mathrm{~N}-163 \mathrm{~N}$.
Nguyen, N. H., C. P. McPhee, and C. M. Wade. 2005. Responses in residual feed intake in lines of Large White pigs selected for growth rate on restricted feeding (measured on ad libitum individual feeding). J. Anim. Breed. Genet. 122:264-270.

Piles, M., and A. Blasco. 2003. Response to selection for growth rate in rabbits estimated by using a control cryopreserved population. World Rabbit Sci. 11:53-62.

Piles, M., E. A. Gomez, O. Rafel, J. Ramon, and A. Blasco. 2004. Elliptical selection experiment for the estimation of genetic parameters of the growth rate and feed conversion ratio in rabbits. J. Anim. Sci. 82:654-660.

Prunier, A., M. Heinonen, and H. Quesnel. 2010. High physiological demands in intensively raised pigs: Impact on health and welfare. Animal 4:886-898.

Richardson, E. C., and R. M. Herd. 2004. Biological basis for variation in residual feed intake in beef cattle. 2. Synthesis of results following divergent selection. Aust. J. Exp. Agric. 44:431-440.

Saintilan, R., I. Merour, L. Brossard, T. Tribout, J. Y. Dourmad, P. Sellier, J. Bidanel, J. van Milgen, and H. Gilbert. 2013. Genetics of residual feed intake in growing pigs: Relationships with production traits, and nitrogen and phosphorus excretion traits. J. Anim. Sci. doi:10.2527/jas.2012-5687

Silverstein, J. T., M. Hostuttler, and K. P. Blemings. 2005. Strain differences in feed efficiency measured as residual feed intake in individually reared Rainbow trout, Oncorhynchus mykiss (Walbaum). Aquacult. Res. 36:704-711. 